Original Article

\title{
SEPARATION AND ASSAY OF FOUR ANTIHISTAMINE DRUGS DIPHENHYDRAMINE, CHLORPHENIRAMINE, CYPROHEPTADINE AND FEXOFENADINE IN PHARMACEUTICAL FORMS BY A SINGLE HPLC METHOD
}

\author{
HANAN SHASHOa, AMIR ALHAJ SAKUR ${ }^{b}$, SALEH TREFI ${ }^{*}$
}

${ }^{a}$ Quality Control and Pharmaceutical Chemistry Department, bAnalytical Chemistry Department-University of Aleppo-Syrian Arab Republic Email: trefi76@yahoo.fr

Received: 17 Jan 2018 Revised and Accepted: 05 Mar 2018

\section{ABSTRACT}

Objective: The objective of this study was to develop and validate a single HPLC method, in order to separate and assay four antihistamine drugs diphenhydramine, chlorpheniramine, cyproheptadine and fexofenadine in pharmaceutical forms. This method was a practical additional choice in quality control laboratories.

Methods: The chromatographic conditions comprised of a classical $C_{18}$-type stationary phase $(150 \times 4.6 \mathrm{~mm}, 5 \mu)$, with a mobile phase consisting of, $2.5 \mathrm{~g}$ of sodium octane sulfonic acid in a mixture of $500 \mathrm{ml}$ of deionized water and $500 \mathrm{ml}$ of acetonitrile, and apparent pH of 2.0 was adjusted with phosphoric acid. The flow rate was $1 \mathrm{ml} / \mathrm{min}$; the detection wavelengths were at $220 \mathrm{~nm}, 230 \mathrm{~nm}, 265 \mathrm{~nm}$ and $254 \mathrm{~nm}$ for diphenhydramine, chlorpheniramine, cyproheptadine and fexofenadine respectively. The temperature was ambient temperature.

Results: The method was validated for linearity with correlation coefficients very close to one, the accuracy with mean recovery values between 95.0-105.0\%, precision with relative standard deviations of the calculated concentrations less than $5.0 \%$ and specificity in the presence of degradation products. Then it was used successfully to separate a mixture of them and to assay these drugs in pharmaceutical forms purchased from Syria.

Conclusion: The results presented in this paper showed that the developed method was simple and applicable, for the separation and determination of the four drugs in their pharmaceutical forms.

Keywords: HPLC, Diphenhydramine, Chlorpheniramine, Cyproheptadine, Fexofenadine

(C) 2018 The Authors. Published by Innovare Academic Sciences Pvt Ltd. This is an open access article under the CC BY license (http://creativecommons.org/licenses/by/4.0/) DOI: http://dx.doi.org/10.22159/ijpps.2018v10i4.24819

\section{INTRODUCTION}

The simple diphenyl derivative diphenhydramine was the first clinically useful member of the ethanolamine series and serves as the prototype. In addition, to antihistaminic action, it is antiemetic, Antitussive, and has sedative properties. It is used in over-the-counter (OTC) sleep-aid products. The propylamine antihistamines are characterized structurally by an sp3 or sp2 carbon, connecting atom with a carbon chain of two additional carbons linking the key tertiary amino, and diaryl pharmacophore moieties. Those propylamines with a saturated carbon connecting moiety are commonly referred to as the pheniramine. Chlorpheniramine was chosen from this group in our study. The dibenzocycloheptene and dibenzocycloheptene antihistamines may be regarded as phenothiazine analogues in which the sulfur atom has been replaced by an isosteric vinyl group cyproheptadine. Cyproheptadine possesses both antihistamine and antiserotonin activity and is used as an antipruritic agent. Sedation is the most prominent side effect, and this is usually brief disappearing after 3 or $4 \mathrm{~d}$ of treatment.

Fexofenadine is a primary oxidative metabolite of terfenadine. Terfenadine was developed during a search for new butyrophenone antipsychotic drugs, as evidenced by the presence of the $\mathrm{N}$ phenylbutanol substituent. Fexofenadine is a second-generation antihistamine, it is selective peripheral $\mathrm{H}_{1}$-receptor blocker that, like produces no clinically significant anticholinergic effects or a1adrenergic receptor blockade at therapeutic doses. No sedative or another central nervous system (CNS) effects have been reported for this drug, (fig. 1) [1].<smiles>CN(C)CCOC(c1ccccc1)c1ccccc1</smiles>

diphenhydramine

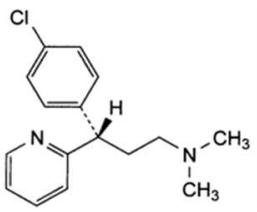

chlorpheniramine

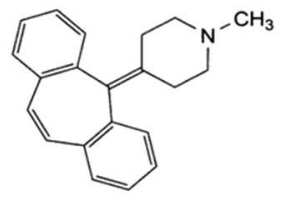

cyproheptadine

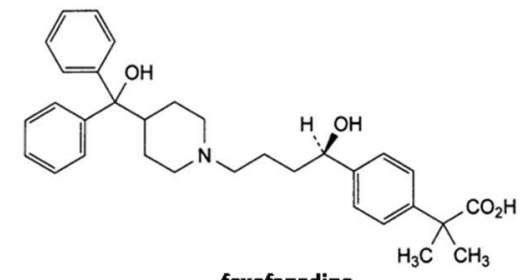

fexofenadine

Fig. 1: Chemical structures of diphenhydramine, chlorpheniramine, cyproheptadine, fexofenadine [2] 
The recommended analytical methods of analyzing diphenhydramine, chlorpheniramine, cyproheptadine, fexofenadine and their related substances as raw materials by the British Pharmacopeia is HPLC, with different conditions, especially the mobile phases, the used columns and other experimental parameters [2].

Other chromatographic methods for analyzing diphenhydramine in formulations, were reported in the bibliography [3-6].

There were also many chromatographic methods, for determining chlorpheniramine in pharmaceuticals, in the bibliography [7-10].

Several analytical methods, such as liquid chromatography have been reported for the determination of cyproheptadine in pharmaceutical formulations [11-13].

There were also many chromatographic methods for assaying fexofenadine in formulations, which have been reported in the bibliography [13-17].

Other antihistamine drugs, such as brompheniramine maleate was estimated by HPLC [18].

The previous HPLC methods used different mobile phases with different parameters. The majority of these methods used a classical elution with buffers. For this reason, we decided to propose a single ion pair HPLC method. This proposed method may be applied to the four drugs with some advantages. The use of octane sulfonic acid in the mobile phase, instead of buffers improves its flowability through the HPLC chain and reduce problems of precipitation of salts on the electrovans, arising from the use of buffers. This technic of elution using a surfactant such as an octane sulfonic acid diminish the pression applied on the column.

In addition, we must update the analytical methods in a regular manner in quality control laboratories, in order to choose the best one.

Therefore, the objective of this work was to develop and validate an additional single HPLC method, for the assay of four antihistamine drugs diphenhydramine, chlorpheniramine, cyproheptadine and fexofenadine in pharmaceutical forms.

\section{MATERIALS AND METHODS}

\section{Chemicals and reagents}

Working standards of diphenhydramine, chlorpheniramine, cyproheptadine and fexofenadine were gifted by Ibn-Alhaytham Industries, Aleppo-Syria. The commercial drugs (brand namekartastamine (diphenhydramine $25 \mathrm{mg}$ Alshahbaa Industries), beloramine (chlorpheniramine $4 \mathrm{mg}$ Mediotech Industries), cyproheptadine (cyproheptadine $4 \mathrm{mg}$ Asia for pharmaceutical industries) and fexofenadine (fexofenadine $120 \mathrm{mg}$ Ibn-Alhaytham Industries) were purchased from Syria; one commercial formulation was analyzed for each active pharmaceutical ingredient. All samples, as received, were stored in the dark at ambient temperature and humidity. They were all analyzed within expiry dates. All the other used reagents were of HPLC grade: acetonitrile (PROLABO), phosphoric acid (MERCK), sodium octane sulfonic acid (TEDIA), Deionized Water for HPLC and syringe filters $0.45 \mu \mathrm{m}$.

\section{Instrumentation}

The HPLC instrument used was an Agilent 1260 infinity, equipped with a UV detector. The $\mathrm{pH}$ meter used was from Crison.

\section{Reference solutions preparation}

A precise quantity of the working standards was accurately weighed, then dissolved in a sufficient volume of deionized water to obtain the starting standard solutions: diphenhydramine $0.4 \mathrm{mg} / \mathrm{ml}$, chlorpheniramine $0.4 \mathrm{mg} / \mathrm{ml}$, cyproheptadine $0.4 \mathrm{mg} / \mathrm{ml}$ and fexofenadine $0.4 \mathrm{mg} / \mathrm{ml}$. These starting standard solutions were used for the preparation of the linearity solutions.

\section{Method development and optimization of chromatographic conditions}

\section{Selection of detection wavelength}

The utilized detection wavelengths were at $220 \mathrm{~nm}, 230 \mathrm{~nm}, 265 \mathrm{~nm}$ and $254 \mathrm{~nm}$ for diphenhydramine, chlorpheniramine, cyproheptadine and fexofenadine respectively.

\section{Column selection}

An Agilent HC-C18 (octadecylsilane) reversed phase column, $150 \mathrm{x}$ $4.6 \mathrm{~mm}$ 5-Micron was utilized.

\section{Mobile phase preparation}

The mobile phase consisting of $2.5 \mathrm{~g}$ of sodium octane sulfonic acid, in a mixture of $500 \mathrm{ml}$ of deionized water and $500 \mathrm{ml}$ of acetonitrile, and apparent $\mathrm{pH}$ of 2.0 was adjusted with phosphoric acid.

\section{Formulation solutions preparation}

Twenty tablets of kartastamine (diphenhydramine $25 \mathrm{mg}$ Alshahbaa Industries), were crushed and powdered, then a quantity of the powder containing $25 \mathrm{mg}$ diphenhydramine was transferred into a $1000 \mathrm{ml}$ volumetric flask containing deionized water, the content was dispersed under magnetic stirring during $20 \mathrm{~min}$ and sonicated for $10 \mathrm{~min}$, until the active pharmaceutical ingredient was well dissolved $(\mathrm{C}=0.025 \mathrm{mg} / \mathrm{ml})$.

Twenty tablets of beloramine (chlorpheniramine $4 \mathrm{mg}$ Mediotech Industries) were crushed and powdered, then a quantity of the powder containing $8 \mathrm{mg}$ diphenhydramine was transferred into a $100 \mathrm{ml}$ volumetric flask containing deionized water, the content was dispersed under magnetic stirring during $20 \mathrm{~min}$ and sonicated for $10 \mathrm{~min}$, until the active pharmaceutical ingredient was well dissolved $(\mathrm{C}=0.08 \mathrm{mg} / \mathrm{ml})$.

Twenty tablets of cyproheptadine (cyproheptadine $4 \mathrm{mg}$ Asia for pharmaceutical industries) were crushed and powdered, then a quantity of the powder containing $8 \mathrm{mg}$ diphenhydramine was transferred into a $100 \mathrm{ml}$ volumetric flask containing deionized water, the content was dispersed under magnetic stirring during 20 min and sonicated for $10 \mathrm{~min}$, until the active pharmaceutical ingredient was well dissolved $(\mathrm{C}=0.08 \mathrm{mg} / \mathrm{ml})$.

Twenty tablets of fexofenadine (fexofenadine $120 \mathrm{mg}$ IbnAlhaytham Industries) were crushed and powdered, then a quantity of the powder containing $120 \mathrm{mg}$ diphenhydramine was transferred into a $1000 \mathrm{ml}$ volumetric flask containing deionized water, the content was dispersed under magnetic stirring during $20 \mathrm{~min}$ and sonicated for $10 \mathrm{~min}$, until the active pharmaceutical ingredient was well dissolved $(\mathrm{C}=0.12 \mathrm{mg} / \mathrm{ml})$.

\section{Degraded starting solutions}

The starting standard solutions prepared as mentioned above were standing at room temperature and sunlight for $60 \mathrm{~d}$. Then, they were analyzed for specificity tests demonstration.

\section{Analytical method validation}

Method validation was performed under a variety of the international conference on harmonization (ICH) recommended test conditions [19].

\section{RESULTS AND DISCUSSION}

\section{HPLC analysis}

The chromatographic conditions comprised of a C18 reversed phase column, $150 \times 4.6 \mathrm{~mm} 5$-Micron, with a mobile phase consisting of $2.5 \mathrm{~g}$ of sodium octane sulfonic acid in a mixture of $500 \mathrm{ml}$ of deionized water and $500 \mathrm{ml}$ of acetonitrile, and apparent $\mathrm{pH}$ of 2.0 was adjusted with phosphoric acid.

The flow rate was $1 \mathrm{ml} / \mathrm{min}$. The utilized detection wavelengths were at $220 \mathrm{~nm}, 230 \mathrm{~nm}, 265 \mathrm{~nm}$ and $254 \mathrm{~nm}$ for diphenhydramine, chlorpheniramine, cyproheptadine and fexofenadine respectively, under ambient temperature.

The reference solutions were injected under the previous chromatographic conditions, the retention times were diphenhydramine $3.8 \mathrm{~min}$, chlorpheniramine $2.7 \mathrm{~min}$, cyproheptadine $5.5 \mathrm{~min}$ and fexofenadine $4.3 \mathrm{~min}$. we should mention that the peak at $1.5 \mathrm{~min}$ in chlorpheniramine chromatogram was for the maleate (fig. 2). 

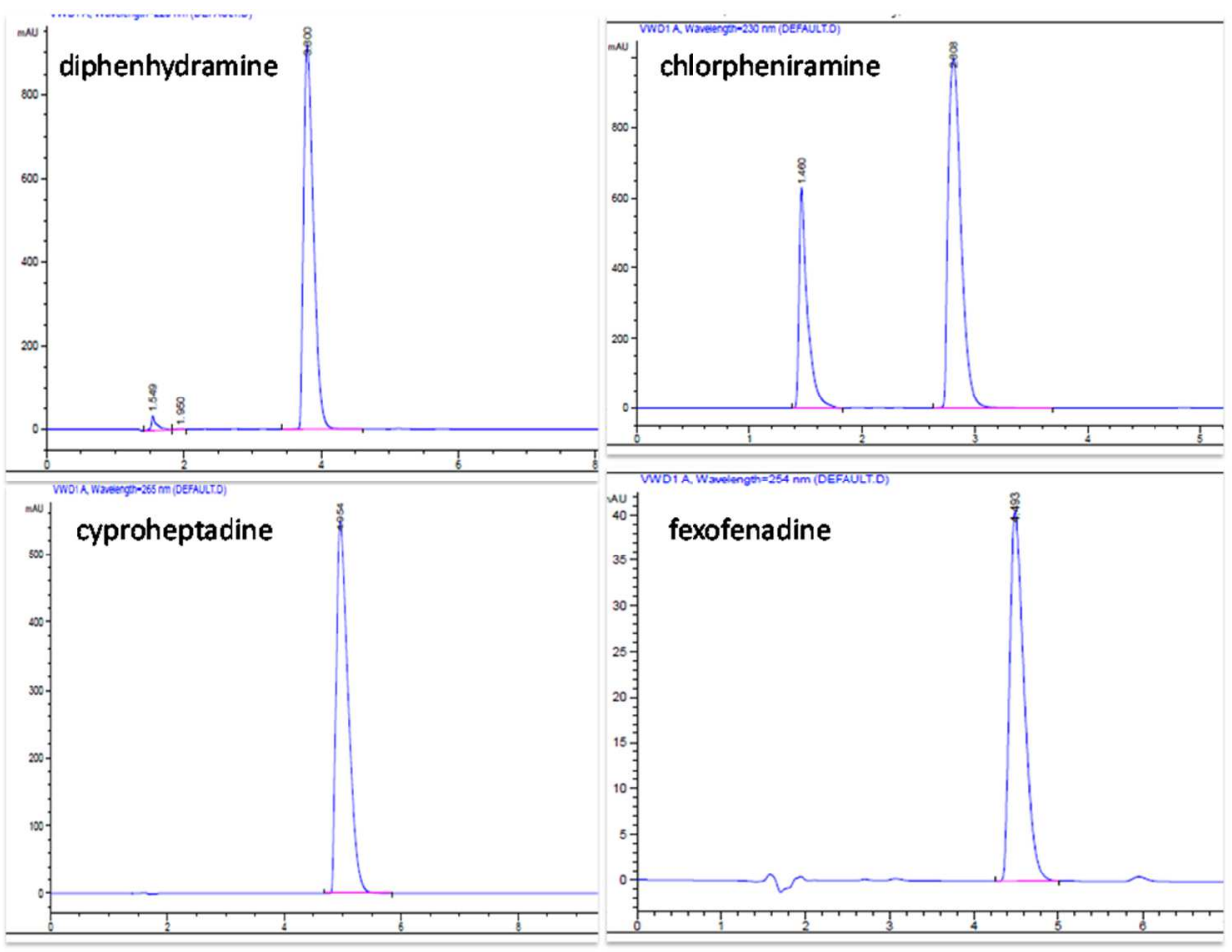

Fig. 2: Chromatograms of diphenhydramine, chlorpheniramine, cyproheptadine, fexofenadine

\section{Analytical method validation}

\section{Linearity}

The linearity of analytical procedure: is its ability (within a given range) to obtain test results which are directly proportional to the concentration of an analyte in the sample [19].

The linearity was evaluated by linear regression analysis, which was calculated by the least square regression method. Five concentrations over the working range were prepared for each drug; this process was done three different times during three weeks $(n=3)$. (fig. 3) showed the regression lines of diphenhydramine, chlorpheniramine, cyproheptadine and fexofenadine with the correlation coefficients $\left(\mathrm{R}^{2}\right)$ given in table 1 . All the correlation coefficients were very close to one, so the developed method was linear for analyzing the four drugs.

\section{Range}

The linearity was demonstrated in the interval $(0.025-0.4 \mathrm{mg} / \mathrm{ml})$ for diphenhydramine, $(0.025-0.4 \mathrm{mg} / \mathrm{ml})$ chlorpheniramine, $(0.025$ $0.4 \mathrm{mg} / \mathrm{ml})$ cyproheptadine and $(0.025-0.4 \mathrm{mg} / \mathrm{ml})$ for fexofenadine.
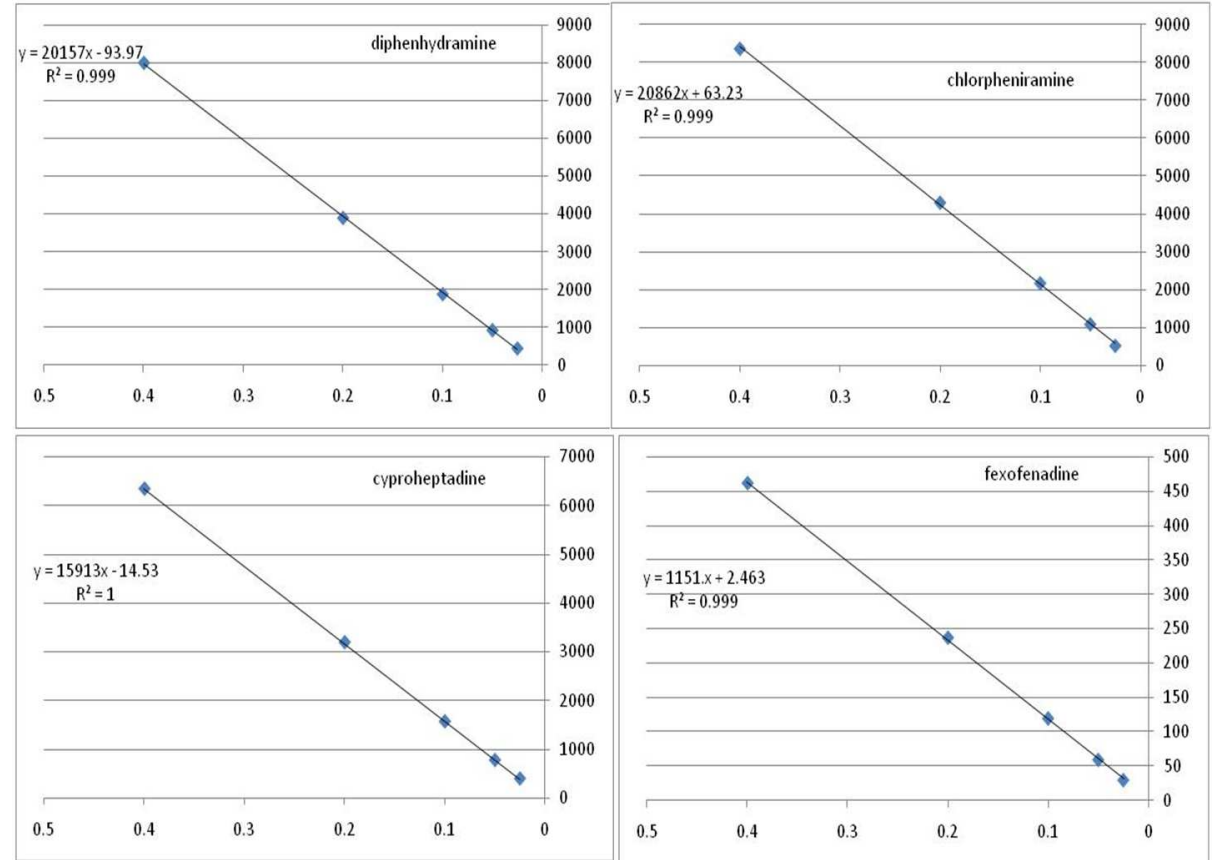

Fig. 3: Linearity lines of diphenhydramine, chlorpheniramine, cyproheptadine, fexofenadine 
Table 1: Correlation coefficients of diphenhydramine, chlorpheniramine, cyproheptadine, fexofenadine

\begin{tabular}{|c|c|c|c|c|}
\hline & Diphenhydramine & Chlorpheniramine & Cyproheptadine & Fexofenadine \\
\hline Correlation coefficients ${ }^{\mathrm{a}}\left(\mathrm{R}^{2}\right)$ & $\mathrm{R}^{2}=0.999$ & $\mathrm{R}^{2}=0.999$ & $\mathrm{R}^{2}=1$ & $\mathrm{R}^{2}=999$ \\
\hline Equation $^{\mathrm{a}}$ & $y=20157 x-93.97$ & $y=20862 x+63.23$ & $y=15913 x-14.53$ & $y=1151 . x+2.463$ \\
\hline
\end{tabular}

${ }^{a} n=3$ : five concentrations over the working range, were prepared for each drug; this process was done three different times during three weeks.

\section{Accuracy}

The accuracy of an analytical procedure: expresses the closeness of agreement between the value which is accepted either as a conventional true value or an accepted reference value and the value found. For the quantitative approaches, at least nine determinations across the specified range should be obtained [19].

Three concentration levels $(0.05,0.1$, and $0.2 \mathrm{mg} / \mathrm{ml})$ have been used to study the accuracy of diphenhydramine. The results indicated that the individual recovery ranged from $97.99 \%$ to $101.68 \%$. The recovery of diphenhydramine by the proposed method was accepted, as the mean recovery value was 99.55 between $95.0-105.0 \%$ with RSD value 1.92 not more than $5.0 \%$.

Three concentration levels also $(0.05,0.1$, and $0.2 \mathrm{mg} / \mathrm{ml})$ have been used to study the accuracy of chlorpheniramine. The individual recovery ranged from $99.12 \%$ to $101.76 \%$. The recovery of chlorpheniramine by the proposed method was accepted, as the mean recovery value, 100.77 was between $95.0-105.0 \%$ with RSD value 1.43 not more than $5.0 \%$.

Three concentration levels $(0.05,0.1$, and $0.2 \mathrm{mg} / \mathrm{ml})$ have been used to study the accuracy of cyproheptadine. The individual recovery of cyproheptadine ranged from $98.71 \%$ to $100.68 \%$. The recovery of cyproheptadine by the proposed method was accepted, as the mean recovery value, 99.55 was between $95.0-105.0 \%$ with RSD value 1.02 not more than $5.0 \%$.

Finally, three concentration levels $(0.05,0.1$, and $0.2 \mathrm{mg} / \mathrm{ml})$ have been used to study the accuracy of fexofenadine. The individual recovery of fexofenadine ranged from $97.85 \%$ to $101.64 \%$. The recovery of fexofenadine by the proposed method was accepted, as the mean recovery value, 100.25 was between $95.0-105.0 \%$ with RSD value 2.08 not more than $5.0 \%$ table 2 .

Table 2: Mean recoveries of three concentration levels solutions of the four drugs

\begin{tabular}{|c|c|c|c|c|}
\hline & Diphenhydramine & Chlorpheniramine & Cyproheptadine & Fexofenadine \\
\hline Mean concentration level ${ }_{1}(0.2 \mathrm{mg} / \mathrm{ml}) \%^{\mathrm{a}}$ & $98.97 \pm 6.06$ & $101.76 \pm 2.40$ & $100.68 \pm 2.82$ & $101.64 \pm 3.92$ \\
\hline Mean concentration level $2(0.1 \mathrm{mg} / \mathrm{ml}) \%^{\mathrm{a}}$ & $97.99 \pm 6.88$ & $101.43 \pm 2.48$ & $99.25 \pm 2.30$ & $101.25 \pm 4.58$ \\
\hline Mean concentration level $3(0.05 \mathrm{mg} / \mathrm{ml}) \% \mathrm{a}$ & $101.68 \pm 7.77$ & $99.12 \pm 3.18$ & $98.71 \pm 1.58$ & $97.85 \pm 4.90$ \\
\hline Mean recovery $\%( \pm)$ SD & $99.55 \pm 1.90$ & $100.77 \pm 1.44$ & $99.55 \pm 1.01$ & $100.25 \pm 2.08$ \\
\hline RSD & 1.92 & 1.43 & 1.02 & 2.08 \\
\hline
\end{tabular}
RSD 1.92 1.43 2.08

${ }^{\mathrm{a}}$ mean $\pm \mathrm{SD}, \mathrm{n}=3$.

\section{Precision}

The precision of an analytical procedure: expresses the closeness of agreement between a series of measurements obtained from multiple sampling of the same homogeneous sample under the prescribed conditions [19]

Intermediate Precision: The solutions $0.1 \mathrm{mg} / \mathrm{ml}$ of diphenhydramine, $0.1 \mathrm{mg} / \mathrm{ml}$ of chlorpheniramine, $0.1 \mathrm{mg} / \mathrm{ml}$ of cyproheptadine and $0.1 \mathrm{mg} / \mathrm{ml}$ of fexofenadine have been prepared at three different times, by three analysts during three weeks, each solution was injected two times $(\mathrm{N}=6)$. Relative standard deviations of the calculated concentrations (RSD) were given in table 3 .

The RSD of diphenhydramine was $7 \%, 2.45 \%$ for chlorpheniramine, $2.32 \%$ for cyproheptadine and $4.52 \%$ for fexofenadine (not more than $5.0 \%$, except for diphenhydramine which was $7 \%$ ). These results indicated that the intermediate Precision of this method was accepted for diphenhydramine, and was good for chlorpheniramine, cyproheptadine and fexofenadine.

Table 3: Relative standard deviation of the six assays of solutions of the four drugs

$\left.\begin{array}{llll}\hline \mathbf{N} & \begin{array}{l}\text { Diphenhydramine (0.1 } \\ \mathbf{m g} / \mathbf{m l})\end{array} & \begin{array}{l}\text { Chlorpheniramine (0.1 } \\ \mathbf{m g} / \mathbf{m l})\end{array} & \begin{array}{l}\text { Cyproheptadine (0.1 } \\ \mathbf{m g} / \mathbf{m l})\end{array} \\ \hline 1 & 0.093 & 0.102 & 0.099 \\ 2 & 0.094 & 0.102 & 0.098 \\ \mathbf{m g} / \mathbf{m l})\end{array}\right)$

${ }^{a} n=6$.

\section{Specificity}

Specificity is the ability to assess unequivocally the analyte in the presence of components, which may be expected to be present. Typically, these might include impurities, degradants, matrix, etc [19].

The chromatograms of the reference solutions before degradation indicated no additional peaks other than those of diphenhydramine $3.8 \mathrm{~min}$, chlorpheniramine $2.7 \mathrm{~min}$, cyproheptadine $5.5 \mathrm{~min}$ and fexofenadine $4.3 \mathrm{~min}$ and the peak at $1.5 \mathrm{~min}$ in chlorpheniramine chromatogram was for the maleate (fig. 2).

In order to demonstrate the specificity of the method, reference solutions were exposed to sunlight for $60 \mathrm{~d}$ at room temperature. Then, they were recorded.

The chromatogram of the standing reference solution of diphenhydramine showed many additional peaks, but they were 
well resolved from the peak of diphenhydramine with a significant

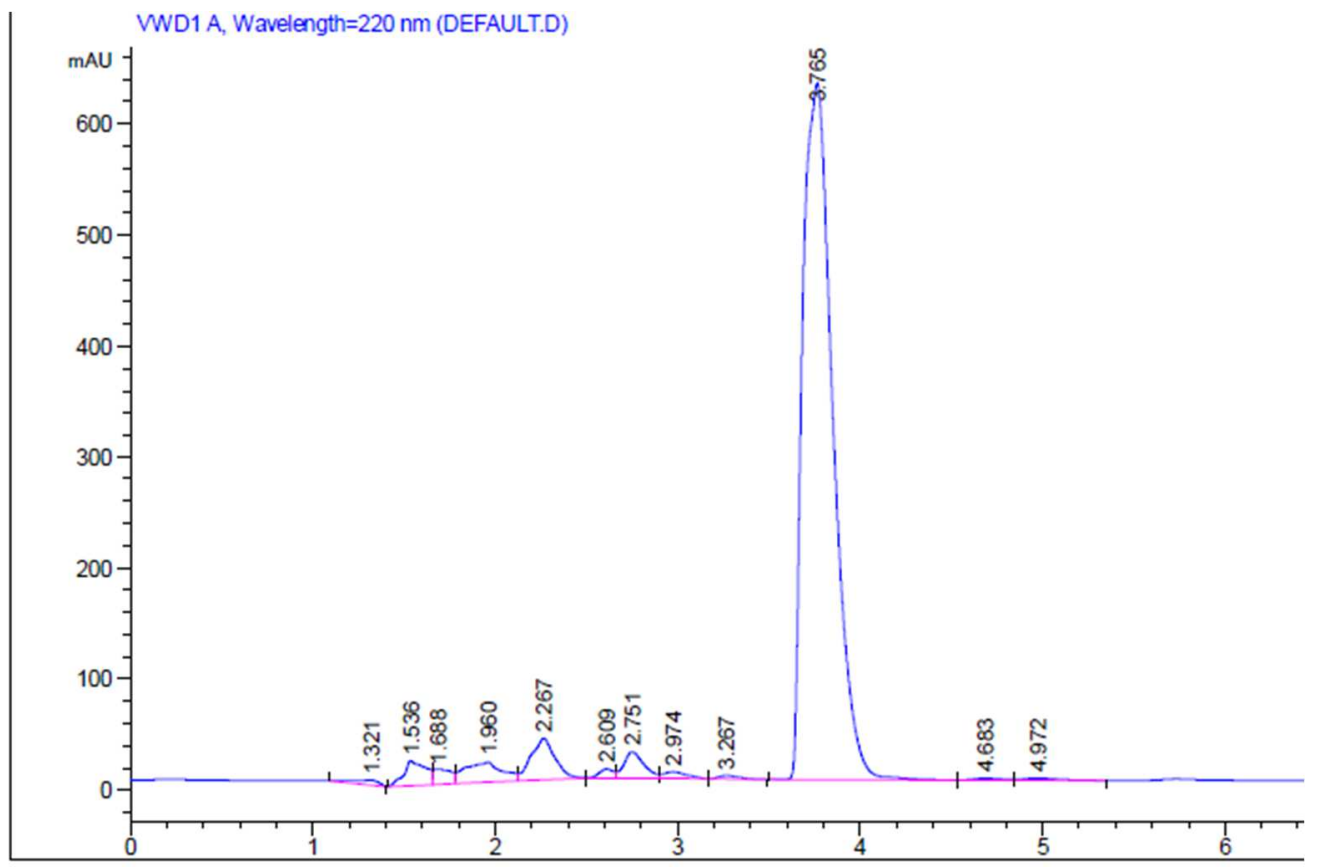

Fig. 4: Chromatogram of the standing reference solution of diphenhydramine

The chromatogram of the standing reference solution of chlorpheniramine showed other peaks in addition to the major one

and the maleate peak, but they were separated from the peak of chlorpheniramine (fig. 5).

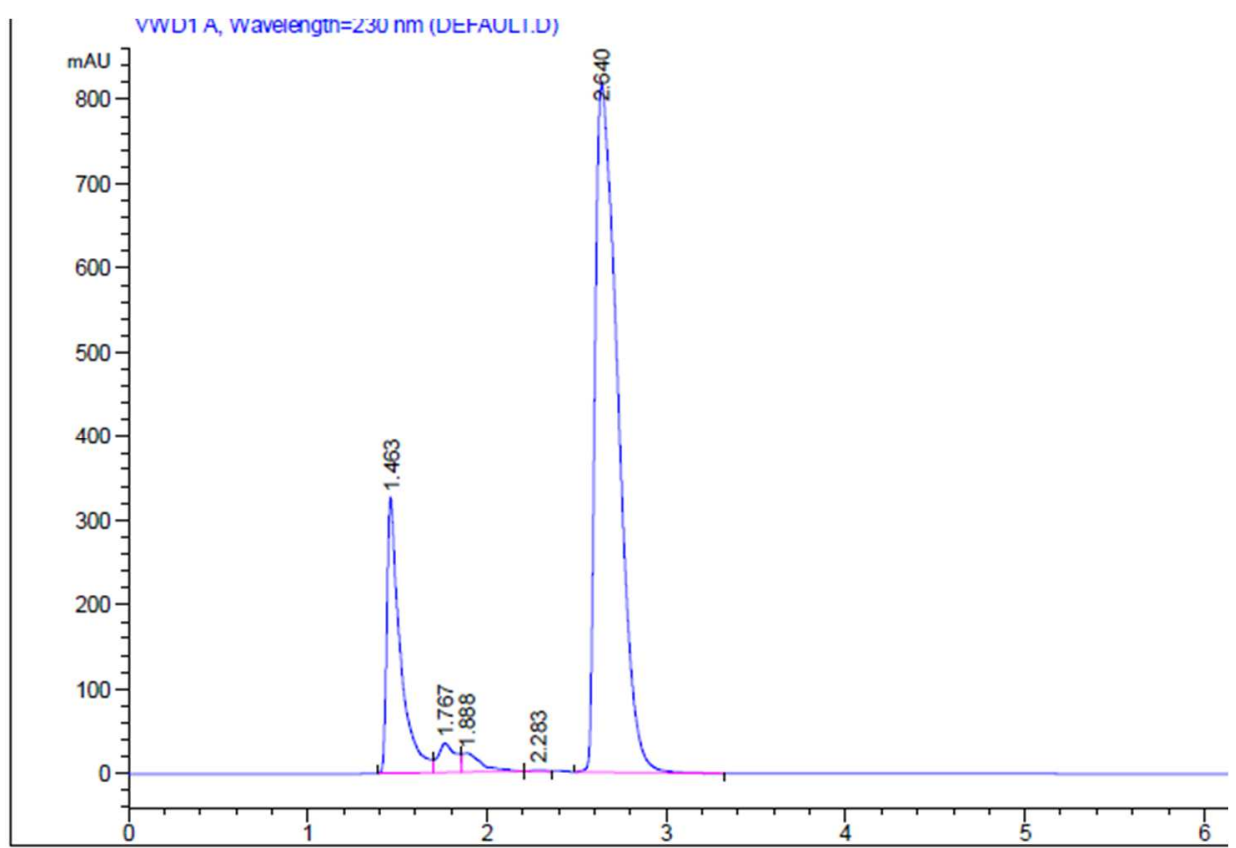

Fig. 5: Chromatogram of the standing reference solution of chlorpheniramine

The chromatograms of the standing reference solution of cyproheptadine showed several additional peaks, appeared before the main peak with no interference (fig. 6).

The chromatograms of the standing reference solution of fexofenadine showed two additional peaks, appeared after the main peak. In this case, there was no separation between the main peak and one of the degradation peaks (fig. 7).
As a result, this method was well specific for the assay of diphenhydramine, chlorpheniramine, cyproheptadine, in the presence of their degradation products. In order to separate the fexofenadine from the degradation peak, modification of this method must be applied.

On the other hand, tests for peak homogeneity were needed by using diode array detection or mass spectrometry but we did not dispose of these techniques [19]. 


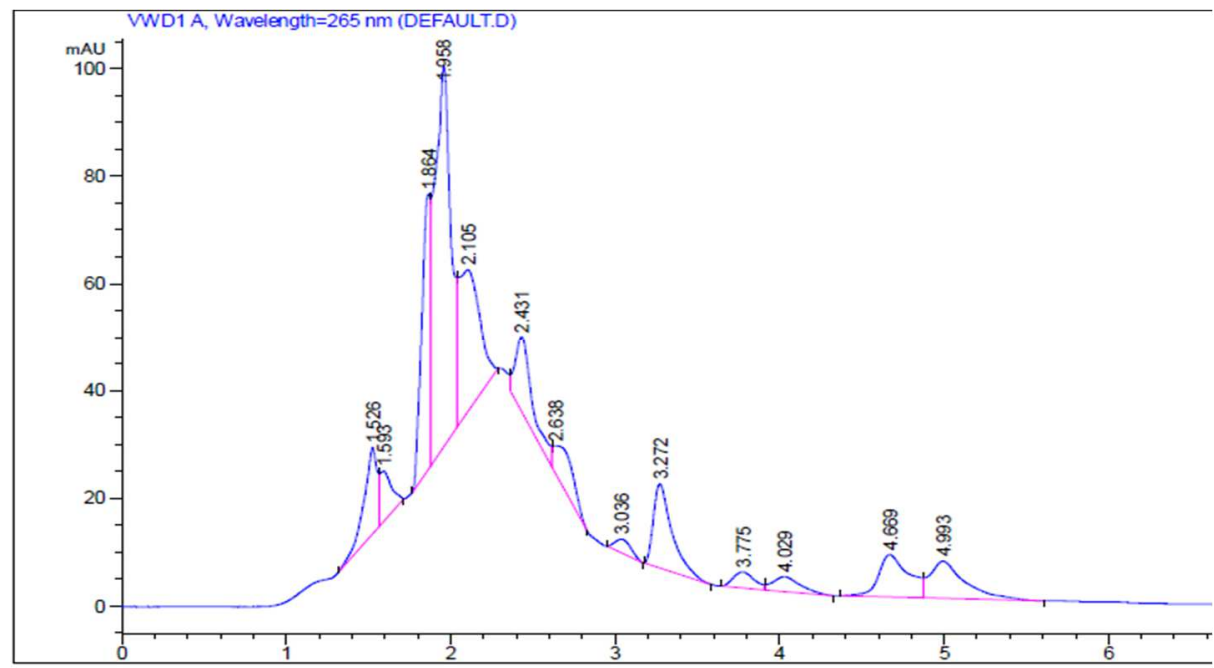

Fig. 6: Chromatogram of the standing reference solution of cyproheptadine

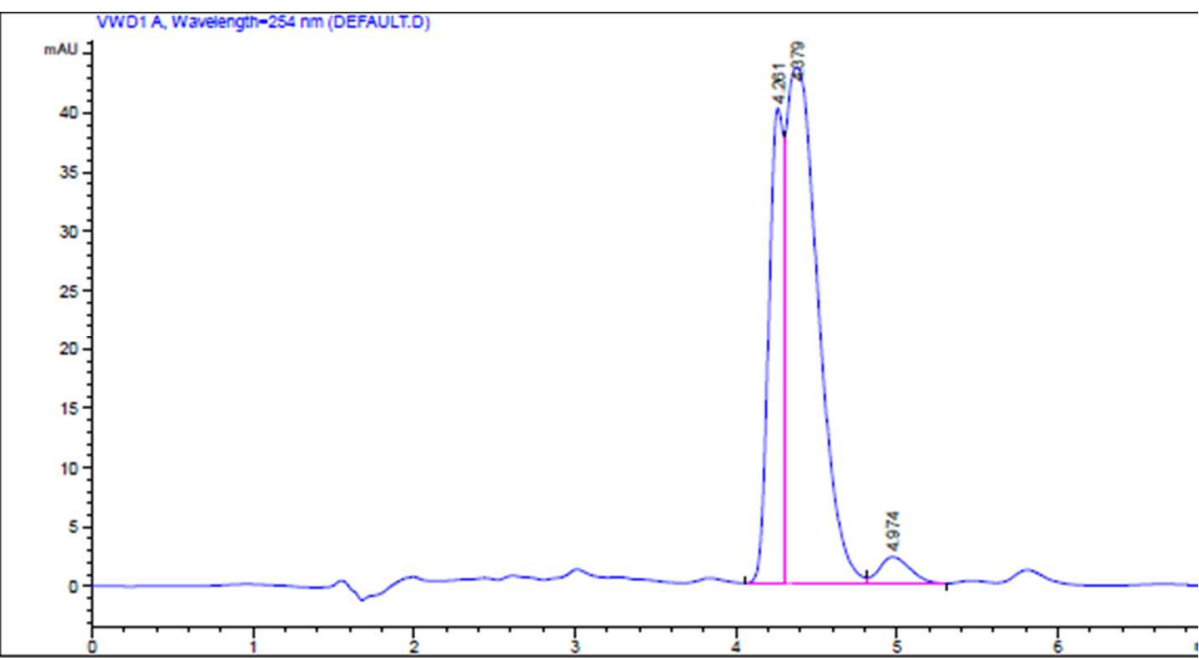

Fig. 7: Chromatogram of the standing reference solution of fexofenadine

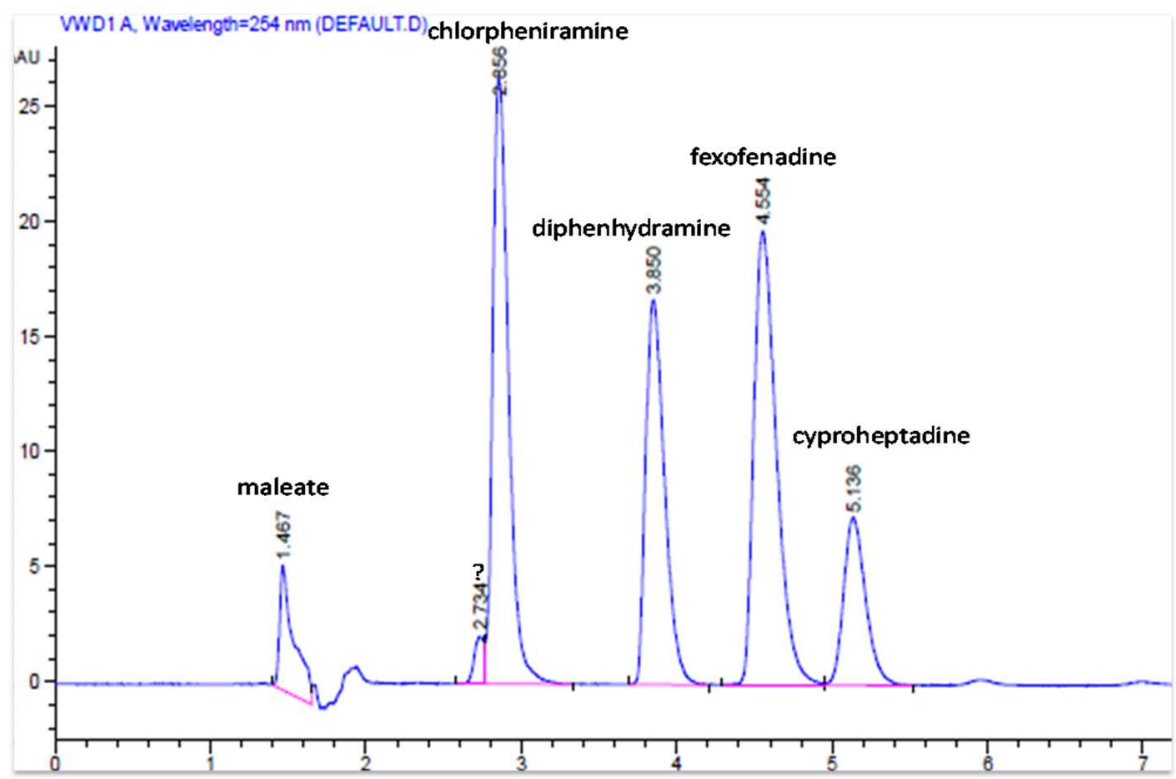

Fig. 8: Chromatogram of a mixture of diphenhydramine, chlorpheniramine, cyproheptadine, fexofenadine 
Separation of diphenhydramine, chlorpheniramine, cyproheptadine and fexofenadine mixture

This new chromatographic method was applied literally, to separate a solution contains the four drugs together as a mixture. $254 \mathrm{~nm}$ was used as a common detection wavelength. The chromatogram showed a complete separation without any interference between the peaks of diphenhydramine $3.8 \mathrm{~min}$, chlorpheniramine $2.8 \mathrm{~min}$, cyproheptadine $5.1 \mathrm{~min}$ and fexofenadine $4.5 \mathrm{~min}$. (fig. 8).

\section{Pharmaceutical forms assay}

Finally, we applied our method to assay commercial tablets purchased from Syria, which contained the four antihistamine drugs. One formulation was analyzed for each drug. The data of tablets contents were reported in table 5. It was observed that, not all the formulations tested had concentrations within the specification of the USP Pharmacopeia, which recommended that tablets should contain not less than $90 \%$ and not more than $110 \%$ of the labelled amount of the active pharmaceutical ingredient for diphenhydramine, chlorpheniramine and cyproheptadine and not less than $95 \%$ and not more than $105 \%$ for fexofenadine [20]. Diphenhydramine and cyproheptadine tablets contained the active pharmaceutical ingredient, within the range $90-110 \%$ of the stated concentration with RSD not more than $5 \%$. But chlorpheniramine tablets contained $88.42 \%$ of the active pharmaceutical ingredient, of the stated concentration with RSD $2.56 \%$ which was out of the specification. Fexofenadine tablets content was also out of specification with $90.33 \%$ of the active pharmaceutical ingredient with RSD 1.04\%.

Nalluri B. N et al. result of assaying diphenhydramine tablets was $99.97 \pm 0.234$ [5]. Vishal Jain et al. found $100.25 \%$ of chlorpheniramine in formulations [7]. Rajan V. Rele. Determination of fexofenadine hydrochloride in pharmaceutical dosage form By HPLC was accurate [17].

The results reported herein demonstrated that the quality of tablets of diphenhydramine, chlorpheniramine, cyproheptadine and fexofenadine sold in Syria was not totally correct.

Table 5: Results of tablets assay by the developed HPLC method

\begin{tabular}{|c|c|c|c|c|c|}
\hline FormulationName & Active ingredient and potency & $\begin{array}{l}\text { Manufacturer name and } \\
\text { country of production }\end{array}$ & Number of tablets & Drug content $\%( \pm) S^{a}$ & RSD \\
\hline Kartastamine & diphenhydramine $25 \mathrm{mg}$ & Alshahbaa Industries (Syria) & 20 & 95.76 & 2.36 \\
\hline Beloramine & chlorpheniramine $4 \mathrm{mg}$ & Mediotech Industries (Syria) & 20 & 88.42 & 2.56 \\
\hline Cyproheptadine & cyproheptadine $4 \mathrm{mg}$ & Asia (Syria) & 20 & 101.81 & 0.31 \\
\hline Fexofenadine & fexofenadine $120 \mathrm{mg}$ & Ibn-Alhaytham (Syria) & 20 & 90.33 & 1.04 \\
\hline
\end{tabular}

amean $\% \pm \mathrm{SD}, \mathrm{n}=3$.

\section{CONCLUSION}

A simple, accurate and improved ion-pair HPLC method has been developed for the determination of four antihistamine drugs diphenhydramine, chlorpheniramine, cyproheptadine and fexofenadine in pharmaceutical forms. This method was utilized to separate a mixture of the four drugs. It was applied to assay commercial formulations sold in Syria. This method could be an additional analytical technique particularly in the quality control of raw materials, active pharmaceutical ingredients and pharmaceutical formulations. The results reported herein demonstrated that the quality of the analyzed formulations of diphenhydramine, chlorpheniramine, cyproheptadine and fexofenadine in sold in Syria was not totally correct.

\section{ACKNOWLEDGEMENT}

This research work was supported by the University of Aleppo.

\section{ABBREVIATIONS}

OTC: over-the-counter, CNS: central nervous system, C18: octadecylsilane, ICH: the international conference on harmonization.

\section{AUTHORS CONTRIBUTIONS}

The study was carried out in collaboration among all the authors. The idea was developed by Saleh Trefi, the analysis was done by Hanan Shasho, optimization was done by Amir Alhaj sakur. The manuscript was written by Saleh Trefi.

\section{CONFLICT OF INTERESTS}

There is no conflict of interest between authors

\section{REFERENCES}

1. JH Block, JM Beale. Wilson, Gisvold's. Textbook of organic medicinal and pharmaceutical chemistry. $11^{\text {th }}$ ed. Philadelphia: Lippincott Williams and Wilkins; 2004. p. 485-520.

2. British Pharmacopeia on Line; 2015.

3. Vinutha K, Saba M, Medidi S. Development and validation of stability-indicating HPLC method for simultaneous determination of related substances of acetaminophen and diphenhydramine hydrochloride in rapid release gel capsules. Am J Pharm Tech Res 2016;6:411-26.

4. Mohammed Al B, Gunasekar M. Simultaneous estimation of diphenhydramine hydrochloride and naproxen sodium in raw and tablet formulation by the reverse phase high-performance liquid chromatographic method. Int Res J Pure Appl Chem 2016;13:1-9.

5. Nalluri BN, Mrudula B, Chitralatha K, Sultana SA, Chandra TU. Development of stability indicating RP-HPLC-PDA method for the simultaneous analysis of naproxen sodium and diphenhydramine hydrochloride in bulk and tablet dosage forms. Indian Drugs 2015;52:40-7.

6. Hatice Ç, Ebru B. HPLC method development and validation: simultaneous determination of active ingredients in a cough and cold pharmaceuticals. Int J Pharm Pharm Sci 2014;6:421-8.

7. Vishal J, Mukesh CS. Validated RP-HPLC method for determining the levels of bromhexine $\mathrm{HCl}$, chlorpheniramine maleate, dextromethorphan $\mathrm{HBr}$ and guaiphenesin in their pharmaceutical dosage forms. J Taibah Uni Sci 2016;10:38-45.

8. Kapildev RJ. Analytical method development and validation of RP HPLC for simultaneously estimation of chlorpheniramine maleate, dextromethorphan hydrobromide, phenylephrine hydrobromide in cough syrup. Int J Adv Sci Engin Tech 2016;4:35-9.

9. Sher N, Siddiqui FA, Hasan N, Shafi N, Zubair A, Mirza AZ. Simultaneous determination of antihistamine anti-allergic drugs, cetirizine, domperidone, chlorphenamine maleate, loratadine, meclizine and buclizine in pharmaceutical formulations, human serum and pharmacokinetics application. Anal Methods 2014;6:2704-14.

10. Sehrawat R, Khatak M, Maithani M, Khatak S. Simultaneous determination of Chlorpheniramine Maleate, paracetamol and phenylephrine hydrochloride in tablet dosage form by highperformance liquid chromatography. Int J Drug Dev Res 2013;5:258-63.

11. Fanhua C, Yumei Z, Xiaona Z. Determination of content and related substances of cyproheptadine hydrochloride tablets by HPLC. China Pharm 2015;18:1827-9.

12. Alaa El-G, Moustafa MM. HPLC and chemometric methods for the simultaneous determination of cyproheptadine hydrochloride, multivitamins, and sorbic acid. J Pharm Biomed Anal 2004;35:703-13. 
13. Burrows GW, Alliger CL. High-performance liquid chromatographic determination of cyproheptadine hydrochloride in tablet formulations. J Pharm Sci 1983; 72:1212-3.

14. Agha ZM, Arayne MS, Najma S. HPLC method development, validation and its application to investigate in vitro effect of pioglitazone on the availability of $\mathrm{H} 1$ receptor antagonists. J Associ Arab Univ Basic Appl Sci 2017;22:70-5.

15. Ruhul K, Moniruzzaman Sarker ASM, Zakir Sultan M, Sarowar Jahan M. A simple and improved HPLC-PDA method for simultaneous estimation of fexofenadine and pseudoephedrine in extended release tablets by response surface methodology. J Chem 2017:31-6. https://doi.org/10.1155/2017/9395023

16. Barabde GR, Ambadekar SR, Ahmed AN. Comparative study of estimation of fexofenadine hydrochloride by uv-visible spectrophotometry and HPLC method. J Res Pharm Sci 2016;2:1-4.

17. Rajan VR. Determination of fexofenadine hydrochloride in pharmaceutical dosage form by reverse phase high performance liquid chromatography method. Pharm Lett 2016;8:224-8.

18. Wicharn J, Puangkaew L. Development of HPTLC method for determination of brompheniramine maleate and phenylephrine hydrochloride tablets. Int J Pharm Pharm Sci 2014;6:106-9.

19. http://www.ich.org/fileadmin/Public_Web_Site/ICH_Products /Guidelines/Quality/Q2_R1/Step4/Q2_R1_Guideline.pdf [Last accessed on 10 Dec 2017]

20. United Stated Pharmacopoeia USP 38/National Formulary NF $33 ; 2015$. 